\title{
Respiratory Control in the Parents of Sudden Infant Death Syndrome Victims. Ventilatory Control in SIDS Parents
}

\author{
CLIFFORD ZWILLICH, ${ }^{(26)}$ ROBERT MCCULLOUGH, CHRISTIAN GUILLEMINAULT, \\ JOSEPH CUMMISKEY, AND JOHN V. WEIL
}

Cardiovascular Pulmonary Research Laboratory and Pulmonary Division, University of Colorado Medical Center. Denver, Colorado and Stanford University Sleep Disorder Clinic and Research Center, Stanford, California, USA

\section{Summary}

To determine if a familial abnormality in the control of breathing might explain the reasons for the sudden infant death syndrome (SIDS), three groups of parents were studied. The first $(N=8$ sets of parents) had one infant die of SIDS (one SIDS), whereas the second $(N=6)$ had a SIDS victim plus a second child with a "near-miss" occurrence (two SIDS). When compared to the third group (controls), these parents demonstrated no abnormality in the ventilatory response to hypoxia or hypercapnia. Similarly, they had normal respiratory frequency, tidal volume, inspiratory time, and arterial blood gas tensions. We conclude that a familial abnormality in breathing control measured during wakefulness is not the basis for SIDS.

\section{Speculation}

Respiration during sleep may be abnormal in SIDS parents even though no alterations in the control of breathing were found during daytime studies.

The Sudden Infant Death Syndrome (SIDS) is the most common cause of infant death between the ages of one month and one year. In some cases, death is preceded by recurrent sleep apnea which is severe enough to cause both cyanosis and bradycardia (near-miss SIDS episode) (7, 19). Chronic hypoxemia may precede sudden infant death (15). Alveolar hypoventilation during normal sleep has also been documented in near-miss infants (18), suggesting a mechanism which may explain the hypoxemia. Furthermore, these infants have decreased ventilatory responses to hypercapnia (18) and increased periodic breathing during hypoxia (1), suggesting that the hypoventilation may be due to an abnormality in the control of breathing.

Abnormalities in the control of breathing measured while awake have been described in other patients who demonstrated both chronic alveolar hypoventilation and sleep apnea. These include patients with idiopathic alveolar hypoventilation $(10,11)$, the obesity hypoventilation syndrome $(20,23)$, and those suffering from myotonic dystrophy $(2,3)$. Recent studies in twins (4), endurance athletes (17), and some patients with idiopathic hypoventilation (13) have demonstrated the importance of genetic influences on ventilatory control. Most recently, sleep apnea has been described in patients with chronic obstructive lung disease (5). Those most frequently affected have hypoventilation and also have been shown to have decreased ventilatory drives. Here also, decreased ventilatory drives during wakefulness has been demonstrated in the genetically related family members of these patients (14). These findings raised the possibility that a familial abnormality in breathing control may explain the occurrence of SIDS associated with sleep apnea. Accordingly, the present study was undertaken to determine if such familial factors are operating in SIDS by evaluating the respiratory control during wakefulness in parents of SIDS victims.

\section{METHODS}

\section{SUBJECTS}

Three groups of parents were studied after giving informed consent. The first group (controls) contained 6 sets of parents who had infants born at approximately the same time as those in the other two groups. These parents were similar in age and socioeconomic status to parents in the other groups. Each infant in the control group was monitored for at least $24 \mathrm{hr}$ following delivery and had normal respiratory patterns during sleep (8). All these infants remain well through the first year of life.

The second group (one SIDS) contained 8 sets of parents who had a single infant die of SIDS between one month and one year of life. In each case, no specific cause of death was determined at routine postmortem examination.

The third group (two SIDS) contained 6 families where one infant had died of the syndrome and another had a near-miss episode (sleep apnea associated with cyanosis and bradycardia) which was documented in the hospital.

All parents (subjects) were in good health, and all were considered free of pulmonary disease after completion of a screening questionnaire and spirometry. All were asked to refrain from using any medication on the day of study.

\section{STUDY PROTOCOL}

The investigators performing the study had no knowledge of the parent's group. The parents reported to the laboratory in the fasting state and rested for at least $30 \mathrm{~min}$ in the supine position. A catheter was placed in a vein of a warmed hand $\left(41^{\circ} \mathrm{C}\right)$ for the measurement of arterialized venous $\mathrm{pH}$ and carbon dioxide tension (6). Heart rate was monitored by electrocardiogram. Then, while using television as both an audio and visual distraction, the subjects breathed room air through a respiratory valve while resting minute ventilation, respiratory frequency, tidal volume, and inspiratory time were measured with a hot film anometer flow meter (Thermal System, Inc.). The anometer has a $90 \%$ rise time of $100 \mathrm{msec}$ and is calibrated against a rotameter flow meter and Tissot apparatus.

The ventilatory response to isocapnic hypoxia was measured in duplicate using a technique which has been previously described (21). Briefly, the subject breathed through a Rudolph respiratory valve (Collins Co., Inc.) from which gases were continuously sampled by an infrared carbon dioxide analyzer and by a fuel-cell oxygen analyzer (22). Oxygen, carbon dioxide, and flow signals were fed into an online computer (Nova 1200), the data emerging 
as continuous real-time oscilloscopic plots of end-tidal oxygen tension, end-tidal carbon dioxide tension, and minute ventilation. The end-tidal oxygen plot was used to guide the manual addition of nitrogen to the initial inspired gas $(30 \%$ oxygen and the remainder nitrogen) to produce a gradual fall in end-tidal oxygen tension $\mathrm{P}_{\mathrm{A}} \mathrm{O}_{2}$ from 230 to $40 \mathrm{~mm} \mathrm{Hg}$ over a period of 7 to $8 \mathrm{~min}$. Output from the carbon dioxide analyzer was also displayed on an oscilloscope and used to guide the manual addition of $100 \%$ carbon dioxide to the inspired gas in amounts sufficient to prevent hypocapnia. End-tidal carbon dioxide tension was controlled within $1 \mathrm{~mm} \mathrm{Hg}$ with this technique (21) and was maintained at the $\mathrm{P}_{\mathrm{A}} \mathrm{CO}_{2}$ determined during the initial measurements. The plots of ventilation in relation to $\mathrm{P}_{\mathrm{A}} \mathrm{O}_{2}$ are hyperbolic. To compare curves, a simple empiric equation is used relating ventilation to alveolar $\mathrm{PO}_{2}$ as follows:

$$
\dot{\mathrm{V}}_{E}=\dot{\mathrm{V}}_{O}+\frac{\mathrm{A}}{\mathrm{P}_{A} \mathrm{O}_{2}-32}
$$

where $\dot{V}_{E}$ is minute ventilation in liters/min body temperature and pressure saturated (BTPS), and $\mathrm{P}_{\mathrm{A}} \mathrm{O}_{2}$ is alveolar oxygen tension in millimeters of mercury; $\dot{V}_{0}$ is the asymptote for ventilation obtained by extrapolation, and A determines the shape of the curve such that the higher the value for $A$, the greater the hypoxic ventilatory response (21). In practice, values of these measurements utilize the fact that the relation between ventilation and $1 /\left(P_{A} O_{2}-32\right)$ is linear with a slope of $A$ and an intercept of $\dot{\mathrm{V}}_{\mathrm{O}}$. Slope and intercept ( $\mathrm{A}$ and $\dot{\mathrm{V}}_{\mathrm{O}}$ ) are evaluated with the leastsquares method. Using this curve-fitting technique, $\dot{\mathrm{V}}_{\mathrm{E}}$ can be estimated within $4 \%$ (21)

The hypercapnic ventilatory response was measured with a rebreathing method similar to that described by Read (16), in which a 5-liter rebreathing circuit was filled with $40 \%$ oxygen in nitrogen. Data were collected when inspired $\mathrm{PCO}_{2}$ approached $4 \%$. The ventilatory responses were related to alveolar $\mathrm{PCO}_{2}$ by the equation

$$
\dot{\mathrm{V}}_{E}=\mathrm{S}\left(\mathrm{P}_{\mathrm{A}} \mathrm{CO}_{2}-\mathrm{B}\right)
$$

where $B$ is the extrapolated intercept on the abscissa, and $\mathrm{S}$ is the slope of the response line. Responses are linear with this method.

The data from each group was pooled, and the analysis of variance was used to determine if significant differences existed between the groups.

\section{RESULTS}

Table 1 demonstrates that there was no significant difference in any of the variables in the 3 groups tested. Resting minute ventilation, respiratory frequency, tidal volume, and inspiratory time were all similar. No significant change in $\mathrm{pH}$ or in $\mathrm{PCO}_{2}$ was found between the groups.

Table 1 and Figure 1 show that the mean ventilatory response to hypoxia (A) for the control group was $56.7 \pm 10.9$ (S.E.), which was not significantly different from the mean values found in the
2 groups of parents of SIDS victims. When the distribution of individual responses were compared (not shown), no differences were found between the groups.

The mean ventilatory responses to hypercapnia are also shown in Table 1 and Figure 2, and here also, no differences between the groups were present. The distribution of individual hypercapnic ventilatory responses was also not different between the 3 groups.

\section{DISCUSSION}

The present study shows that the parents of victims of sudden infant death have no measurable abnormalities in the chemical drives to breathe as measured by the ventilatory responses to hypoxia and hypercapnia while awake. The normality of their control of breathing was also demonstrated by normal resting minute ventilation, respiratory frequency, tidal volume, and blood gas values. This is true even for families with more than one episode of SIDS. This last group was selected for study because it was thought that if familial influences in the control of breathing were playing a role in SIDS, these influences would be most obvious in the families with more than one affected infant.

We demonstrated familial abnormalities in the ventilatory responses to hypoxia measured during wakefulness in several entities accompanied by alveolar hypoventilation $(9,13,14)$ and believe that failure to detect any abnormality in SIDS parents suggests that a familial factor in respiratory control is probably not pivotal

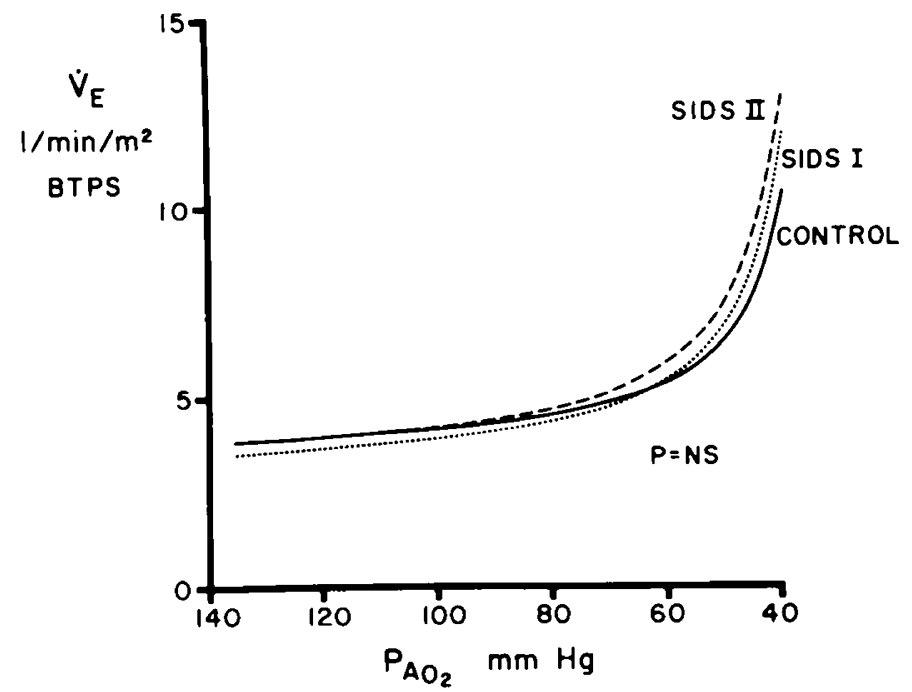

Fig. 1. The ventilatory responses to to hypoxia in the three groups studied are shown above. The mean response of the parents in the SIDS I group (one child with SIDS) and SIDS II group (one child with SIDS plus another with "near miss") was not different from the response in the control group.

\begin{tabular}{|c|c|c|c|}
\hline & Control & One SIDS & Two SIDS \\
\hline No. of parents & 12 & 16 & 12 \\
\hline Age & 30 & 29 & 30 \\
\hline Body surface area $\left(\mathrm{m}^{2}\right)$ & $1.8 \pm 0.005^{1}$ & $1.8 \pm 0.005$ & $1.9 \pm 0.007$ \\
\hline Ventilation (liters $/ \mathrm{min} / \mathrm{m}^{2}$ ) & $4.2 \pm 0.27$ & $4.2 \pm 0.32$ & $4.9 \pm 0.33$ \\
\hline Respiratory frequency & $13 \pm 0.84$ & $12 \pm 0.89$ & $15 \pm 1.10$ \\
\hline Tidal volume (liters $/ \mathrm{m}^{2}$ ) & $0.336 \pm 0.03$ & $0.366 \pm 0.030$ & $0.342 \pm 0.03$ \\
\hline Inspiratory time (sec) & $2.4 \pm 0.15$ & $2.6 \pm 0.25$ & $2.4 \pm 0.16$ \\
\hline $\mathrm{pH}$ & $7.39 \pm 0.008$ & $7.38 \pm 0.005$ & $7.40 \pm 0.006$ \\
\hline $\mathrm{PaCO}_{2}(\mathrm{~mm} \mathrm{Hg})$ & $39 \pm 1.0$ & $39 \pm 0.8$ & $39 \pm 1.1$ \\
\hline Hypoxic ventilation response $\left(\mathrm{A} / \mathrm{m}^{2}\right)$ & $57 \pm 10.9$ & $73 \pm 11.2$ & $79 \pm 13.6$ \\
\hline Hypercapnic ventilation response $\left(\mathrm{S} / \mathrm{m}^{2}\right)$ & $1.0 \pm 0.08$ & $1.2 \pm 0.15$ & $1.1 \pm 0.09$ \\
\hline
\end{tabular}

Table 1. Observations in parents of SIDS victims and controls

\footnotetext{
'Mean \pm S.E.
} 


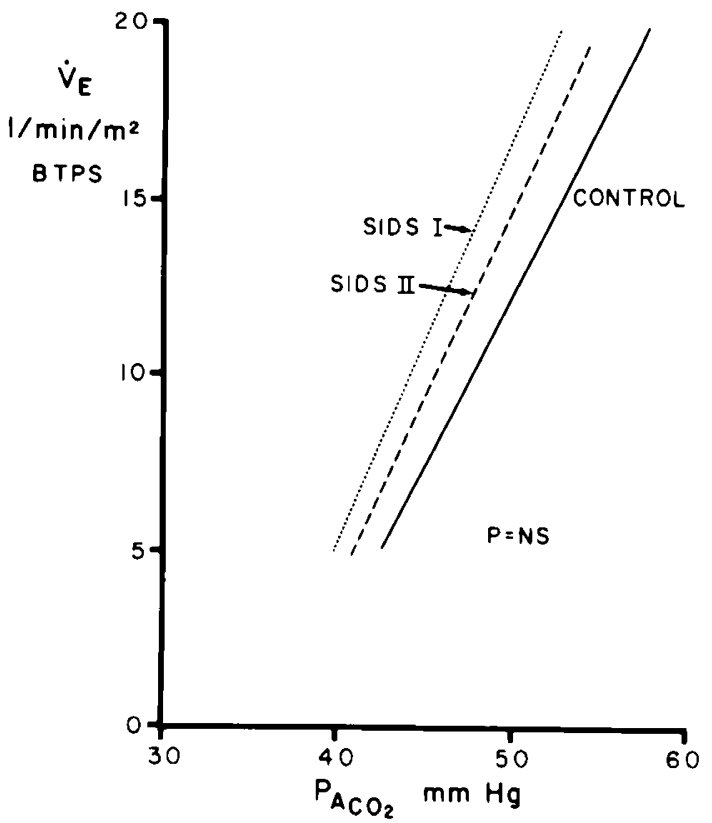

Fig. 2. The mean ventilatory responses to hypercapnia are shown above. The slope of these responses were similar for the three groups studied.

in this syndrome. To further substantiate the lack of importance of genetically mediated abnormalities in breathing control in this syndrome, parents of such infants should be studied during sleep because it may be that deficits in ventilatory drive only present during sleep could predispose to apnea and SIDS, and such deficits may not be evident during wakefulness.

We conclude from this study that a familial abnormality in breathing control measured during wakefulness is not present in the parents of SIDS victims.

\section{REFERENCES AND NOTES}

1. Brady, J. P., Ariagno, R. L., Watts, J. L., Goldman, S. L., and Dumpit: Apnea, hypoxemia, and aborted sudden infant death syndrome. Pediatrics. 62: 686 (1978).

2. Carroll, J. E., Zwillich, C. W., and Weil, J. V.: Ventilatory response in myotonic dystrophy. Neurology, 27: 1125 (1977).

3. Coccagna, G., Mantovani, M., and Parchi, C.: Alveolar hypoventilation and hypersomnia in myotonic dystrophy. J. Neurol. Neurosurg. Psychiatry, 58:977 (1976).

4. Collins, D., Scoggin, C. H., Zwillich, C. W., and Weil, J. V.: Genetic factors in the control of breathing. J. Clin. Invest., 62: 105 (1978).
5. Douglas, N. J., Calverley, P. M. A., Leggett, R. J. E., Brash, H. M.. Flenley, D. C.. and Brezinova, $\mathrm{V}$.: Transient hypoxemia during sleep in chronic bronchitis and emphysema. Lancet, $L: I(1979)$.

6. Forster, H. V., Dempsey, J. A., and Thompson, J.: Estimation of arterial PO., $\mathrm{PCO}_{2}, \mathrm{pH}$ and lactate from arterialized venous blood. J. Appl. Physiol., 32, 134 (1972).

7. Guilleminault, C., Peraita, R., Souquet, M., and Dement, W. C.: Apneas during sleep in infants: possible relationship with sudden infant death syndrome. sleep in infants: possible relationship
Science (Wash. D. C.), 190:677 (1975)

8. Guilleminault, C.. Souquet, M., Ariagno, R., and Dement, W. C.: Abnormal polygraphic findings in near-miss sudden infant death. Lancet, 1326 (1976).

9. Hudgel, D. W., and Weil. J. V.: Asthma associated with decreased hypoxic ventilatory drive: a family study. Ann. Intern. Med., 80: 622 (1974).

10. Kafer, E. R., and Leigh J.: Recurrent respiratory failure associated with absence of ventilatory response to hypercapnia and hypoxemia. Am. Rev. Respir. Dis., 106: 100 (1972).

11. Lugaresi, E., Coccagna. G., and Mantovani, M.: Effects of tracheostomy in two cases of hypersomnia with periodic breathing. J. Neurol. Neurosurg. Psychiatry, 36: 15 (1973).

12. Matthews, A. W., and Howell, J. B. L.: Assessment of responsiveness to carbon dic ride in patients with chronic airways obstruction by rate of isometric inspiratory pressure development. Clin. Sci. Mol. Med., 50: 199 (1976).

13. Moore, L. G., Zwillich. C. W., Battaglia. J., Cotton. E. K., and Weil, J. V. Respiratory failure associated with familial depression of ventilatory response to hypoxia and hypercapnia. N. Engl. J. Med.. 295: 861 (1976).

14. Mountain, R., Zwillich, C. W., and Weil, J. V.: Hypoventilation in chronic obstructive lung disease: role of familial factors. N. Engl. J. Med., 298: 521 (1978)

15. Naeye, R. L.: Hypoxemia and the sudden infant death syndrome. Science (Wash. D. C.), 186: 837 (1974).

16. Read. D. J. C.: A clinical method for assessing the ventilatory response to carbon dioxide. Aust. Ann. Med., 16: 20 (1967).

17. Scoggin, C. H., Doekel, R. D., Kryger, M. H., Zwillich, C. W., and Weil, J. V.: Familial aspects of decreased hypoxic drive in endurance athletes. J. Appl Physiol., 44: 464 (1978).

18. Shannon, D. C., Kelly, D. H., and O'Connell, K.: Abnormal regulation of ventilation in infants at risk for sudden-infant-death syndrome. N. Engl. J. Med 297: 747 (1977).

19. Steinschneider, A.: Prolonged apnea and the sudden infant death syndrome: clinical and laboratory observations. Pediatrics, 50:646 (1972).

20. Tassinairi, C. A., Dalla, B. C., and Cirignotta. F.: Apneic periods and the respiratory related arousal patterns during sleep in the Pickwickian syndrome.

A polygraphic study. Bull. Physio-Pathol. Respir., 8: 1087 (1972)

Weil, J. V., Byrne-Quinn. E., and Sodal, I. E.: Hypoxic ventilatory drive in normal man. J. Clin. Invest., 49: 1061 (1970).

22. Weil, J. V.. Sodal, I. E., and Speck, R. P.: A modified fuel cell for the analysis of oxygen concentration of gases. J. Appl. Physiol., 23: 419 (1967).

23. Zwillich, C. W., Sutton, F. D., Pierson, D. J., Creagh, C. E. and Weil, J. V Decreased hypoxic ventilatory drive in the obesity hypoventilation syndrome. Decreased hypoxic ventilatory drive in the obesity hypoventilation syndrome.
Am. J. Med., 59: 343 (1975).

24. Dr. Zwillich is the recipient of a research career development award from the National Institutes of Health.

25. The authors thank Barbara Fluitt, Margaret Owen, and Eva Toyos for technical assistance.

26. Requests for reprints should be addressed to: Clifford W. Zwillich. M.D. Associate Professor of Medicine, Cardiovascular Pulmonary Research Laboratory, University of Colorado Medical Center. Denver, CO 80262 (USA).

27. This research was supported by a program project grant (HL-14985) and a training grant (HL-05973) from the National Heart, Lung, and Blood Institute and from a National SIDS Foundation Grant.

28. Received for publication April 30, 1979.

29. Accepted for publication August 21, 1979 